\title{
SOCIODEMOGRAPHIC PROFILE OF CHILDHOOD ASTHMA AMONG CHILDREN IN SELANGOR-MALAYSIA
}

\author{
M.J. Surdi Roslan, M.N. Mohd Johari, N.M. Abdul Mubing, H. Harif Fadzilah \\ Faculty of Medicine, MARA University of Technology, Batu Caves, Malaysia
}

Background: Asthma, a reversible chronic inflammatory disease has affected almost 7 million children in the US. In Malaysia, the prevalence of asthma is increasing as it has doubled over the last decade. Sociocultural factors are amongst several factors that could cause asthma. Thus, the need to analyze the above factors pertaining to the local population is vital.

Aim: To find the association between socio-demographic characters and prevalence of asthma among children in Selangor, Malaysia.

Methodology: We conducted a cross sectional study in July 2010. A random sample of 450 children were selected from those attending Selayang Hospital. The child's parents or caregivers were interviewed using questionnaires (modified from ISAAC) which contain socio-demographic characteristics (Age, sex, race, residential area, crowding rate, educational \& occupation of parents). Data analyzed using SPSS 16.

Results: The prevalence of childhood asthma is $24 \%$ and is significantly higher among: Malays than Indian and Chinese $\left(28 \%, 12.8 \%, 2.1 \%\right.$ respectively) $\chi^{2}=20.55$ and children living in urban areas $(25.1 \%)$ than rural areas $(4.3 \%) \chi^{2}=5.132$, OR: 7.356. No significant association found between asthma and: gender; males (24.2\%), female (23.8 \%) OR:0.975); employed mothers $\left(25 \%, \chi^{2}=0.314\right)$; and mothers and fathers with tertiary education $(31.2 \%) \quad \chi^{2}=4.112,(32.7 \%) \quad \chi^{2}=6.287$ respectively. Using logistic regression, no significant relationship between asthma and crowding index $(\mathrm{OR}=1.03$, CI $0.379,2.797)$ found.

Conclusion: Urbanization is a risk factor to childhood asthma particularly for the Malay race. Efficient environmental sanitation is highly recommended. 